\title{
Gastos em Educação e Saude refletem na evolução de Indicadores Sociais? Uma Análise das Despesas Públicas em Petrolina-PE
}

\author{
Maria Eduarda Feitosa dos Reis ${ }^{1}$, Josaias Santana dos Santos ${ }^{2}$, Raimundo Nonato Lima Filho ${ }^{3}$, Hesler Piedade Caffé Filho ${ }^{4}$
}

\begin{abstract}
Resumo: O presente estudo teve por objetivo analisar os gastos em educação e saúde, nos anos de 2005 a 2013 referentes ao município de Petrolina-PE. A Contabilidade Governamental, por sua vez, é a responsável pela evidenciação dessas informações orçamentárias e demais informações sobre o patrimônio público à sociedade e aos administradores públicos. A presente pesquisa é de natureza descritiva e qualitativa, buscando assim evidenciar o impacto dos indicadores de desenvolvimento do município analisado. O referencial teórico buscou abordar o conceito de Estado, seus poderes e funções, o poder executivo municipal, o gasto em educação e saúde e sobre o IFDM - Índice FIRJAN de Desenvolvimento Municipal - que tem como conceito, um estudo do sistema FIRJAN que acompanha anualmente o desenvolvimento socioeconômico de mais de cinco mil municípios brasileiros em três áreas de atuação: Emprego/Renda, Educação e Saúde. Foi desenvolvido em 2008 e é elaborado, exclusivamente, com base em estatísticas públicas oficiais, disponibilizadas pelos ministérios do trabalho, educação e saúde. O resultado da pesquisa mostrou que o município investigado apresenta uma diminuição do gasto per capita em educação nos anos de 2005 a 2006 de -0,18\% e que de acordo com o IFDMEducação, o desenvolvimento desse município nesses dois anos se classificam como regular, a partir de 2007 a 2013 o gasto per capita apresenta um crescimento cerca de $236,51 \%$, afetando de fato no IFDM-Educação oscilando em 2008 de regular para moderado, permanecendo assim de 2009 até 2013. Na Saúde houve uma oscilação de 2005 para 2006 de $-2,43 \%$ e de 2007 a 2011 o gasto per capita apresentou uma variação significativa de $86,15 \%$ e que, por conseguinte, o resultado do desenvolvimento municipal alterou para moderado. Em 2012 o gasto variou para -3,51\% e em 2013 reduziu em 5,96\%, todavia o índice permaneceu ficou estável até o final do período analisado.
\end{abstract}

Palavras-Chave: Gasto Público. Transparência. Educação. Saúde.

\section{Education and Health Expenditures reflect in the evolution of Social Indicators? An Analysis of Public Expenses in Petrolina-PE}

\begin{abstract}
The objective of this study was to analyze spending on education and health, from 2005 to 2013 , in the municipality of Petrolina-PE. Government Accounting, in turn, is responsible for disclosing this budget information and other information about public assets to society and to public administrators. The present research is descriptive and qualitative in nature, aiming to show the impact of development indicators of the analyzed municipality. The theoretical framework sought to address the concept of State, its powers and functions, municipal executive power, spending on education and health, and on IFDM - FIRJAN Municipal
\end{abstract}

\footnotetext{
${ }^{\mathbf{1} B a c h a r e l a ~ e m ~ C i e ̂ n c i a s ~ C o n t a ́ b e i s ~ p e l a ~ F a c u l d a d e ~ d e ~ C i e ̂ n c i a s ~ A p l i c a d a s ~ e ~ S o c i a i s ~ d e ~ P e t r o l i n a, ~ F A C A P E, ~ B r a s i l . ~}$

Contato: dudamreis1505@gmail.com;

${ }^{2}$ Graduado em Ciências Contábeis pela Faculdade de Ciências Aplicadas e Sociais de Petrolina - FACAPE e Especialista em Gestão da Administração Pública pela Universidade Castelo Branco - UCB, Rio de Janeiro - RJ e Mestre em Ciências Contábeis pela FUCAPE Bussines School - FUCAPE, Vitória - ES. Servidor Público Federal, é Contador da Universidade Federal do Vale do São Francisco UNIVASF. É Professor Assistente do Quadro Permanente, atuando na Graduação e Pós-Graduação e é Coordenador Executivo do Programa de Pós-Graduação em Contabilidade e Controladoria Aplicada ao Setor Público (lato sensu) da Faculdade de Ciências Aplicadas e Sociais de Petrolina - FACAPE. Contato: josaias.santana@ facape.br;

${ }^{3}$ Doutor em Controladoria e Contabilidade (USP). Contato: rnlfilho@gmail.com

4 Administrador pela Estácio de Sá; MBA em Gestão Estratégica de Negócios pela Escola de Engenharia Eletromecânica da Bahia; Especialista em Marketing Institucional pela Faculdade São Francisco de Juazeiro; Mestre em Gestão de Políticas Públicas da Universidade Federal do Recôncavo da Bahia. Administrador da Universidade Federal do Vale do São Francisco lotado na Assessoria de Comunicação; Professor da Faculdade São Francisco de Juazeiro: Graduação em Administração e em Comunicação Social e Pós Graduação em Gestão Estratégica e em Marketing; Professor da Universidade Federal do Vale do São Francisco: Pós Graduação em Gestão Pública. Contato: hesler.caffe@univasf.edu.br.
} 
Development Index - which has as its concept a study of the FIRJAN system that accompanies annually the socioeconomic development of more than five thousand Brazilian municipalities in three areas of activity: Employment / Income, Education and Health. It was developed in 2008 and is elaborated exclusively on the basis of official public statistics provided by the ministries of labor, education and health. The results of the research showed that the municipality investigated shows a decrease in per capita expenditure in education in the years 2005 to 2006 of $-0.18 \%$ and according to the IFDM-Education, the development of this municipality in these two years are classified as Regular period, from 2007 to 2013 per capita spending grew by about $236.51 \%$, in effect affecting the IFDM-Education oscillating in 2008 from regular to moderate, remaining from 2009 to 2013. In Health, there was an oscillation of 2005 to 2006 of $-2.43 \%$ and from 2007 to 2011 the per capita expenditure presented a significant variation of $86.15 \%$ and that, consequently, the result of the municipal development changed to moderate. In 2012 the spending varied to $-3.51 \%$ and in 2013 reduced by $5.96 \%$, but the index remained stable until the end of the analyzed period.

keywords: Public Spending. Transparency. Education. Cheers.

\section{Introdução}

Devido ao crescimento populacional no Brasil e no mundo, além da situação socioeconômica desfavorável, aumentou-se a demanda por ações e serviços básicos em saúde pública e educação.

Diante desse cenário, verifica-se a necessidade de gerenciar com maior eficiência e eficácia a utilização do dinheiro público, que passa a ser um importante instrumento na aplicação dos recursos disponíveis para essas áreas.

É por meio de metas e indicadores que ocorre a avaliação sobre a economia, efetividade, eficiência e eficácia do gasto público, cumprindo o papel de fornecer a compreensão de como acontece os processos de escolha e mudança de metas, influenciando a qualidade dos serviços fornecidos e das informações alocadas para a população (Borges \& Matias, 2011).

O conhecimento das condições de saúde da população de um determinado município é uma das atividades centrais do poder público. Com os avanços no controle das doenças infecciosas, passou-se a analisar outras dimensões do estado de saúde, desde as condições de vida até a morbidade. Os indicadores de saúde foram desenvolvidos para facilitar a quantificação e a avaliação das informações produzidas com tal finalidade (RIPSA, 2008).

A Lei 11.494, de 20 de junho de 2007, regulamenta o Fundo de Manutenção e Desenvolvimento da Educação Básica e de Valorização dos Profissionais da Educação- 
FUNDEB e rege a distribuição de recursos do Fundo de Participação dos Municípios (FPM) entre o Distrito Federal, os Estados e seus Municípios. Os valores são pagos ou repassados de acordo com o número de alunos da educação infantil e do ensino fundamental.

O presente trabalho tem objetivo em analisar os gastos por função em educação e saúde nos anos de 2005 a 2013 do município de Petrolina-PE.

A partir dessa conjuntura, este estudo tem a proposta de responder o seguinte problema de pesquisa: De que forma os gastos em Saúde e Educação tem refletido na evolução dos Indicadores de Desenvolvimento Municipal de Petrolina-PE?

Esta pesquisa se justifica por proporcionar uma análise conjuntural sobre a despesa pública e o gasto por função nos setores de saúde e educação relacionada aos oito anos analisados, desse modo, espera-se que este estudo assuma também um caráter social e de controle social, pois o conhecimento sobre esses determinados gastos, poderá contribuir para evidenciar a importância deste campo de conhecimento para a gestão pública no município de Petrolina-PE.

\section{O Estado}

Entende-se sobre Estado uma unidade administrativa de um território; o mesmo é formado pelo conjunto de instituições públicas que representam, organizam e que tem a pretensão de atender os anseios da população que habita o seu território. Entre essas instituições, pode-se citar o governo, as escolas, as prisões, os hospitais públicos, o exército, dentre outras (MOTA, 2012).

O conceito de Estado varia de como ele é considerado. O Estado é pessoa jurídica territorial soberana. Pessoa jurídica é a unidade de pessoas naturais ou de patrimônios, que visa à consecução de certos fins, reconhecida pela ordem jurídica como sujeito de direitos e obrigações (MOREIRA, 2008).

Território é o espaço físico em que o Estado exerce sua soberania. Inclui o solo, o subsolo, as águas interiores, o mar territorial e o espaço aéreo. Já a soberania, no âmbito interno, é o poder supremo consistente na capacidade de autodeterminação e, no âmbito 
externo, é a prerrogativa de receber tratamento igualitário na comunidade internacional (MOREIRA, 2008).

Entretanto, há outros conceitos sobre a definição de Estado como, por exemplo, a impossibilidade de simplesmente entender como uma comunidade que vive num mesmo lugar e protege seus membros dos malfeitores e promove a troca de bens e serviços (SILVA, 2009).

O Estado existe para capacitar todos a viver bem, ou seja, a ter uma vida plena e satisfatória. Isso só pode ser alcançado quando esses grupos familiares ocupam um único e mesmo território (ARISTÓTELES, 2004).

Aristóteles (2004) defende que o Estado é uma associação de homens livres que utiliza o poder político para alcançar a sua finalidade: a promoção da justiça política tem em vista o bem-comum, ou seja, a busca da autossuficiência ou a felicidade da comunidade. O Estado deve por sua vez, promover o bem social de todos, principalmente nos âmbitos que são direitos primordiais a qualquer cidadão: saúde e educação.

De acordo com o Código Civil, o Estado é constituído por uma personalidade jurídica de direito público, na qual devem ter a finalidade de atingir os interesses públicos. O Estado enseja assegurar a vida humana em sociedade; deve garantir a ordem interna, assegurando a soberania na ordem internacional elaborando as regras de conduta e a justiça (BRASIL, 2002).

\section{Poderes do Estado}

Segundo Moreira (2008), os poderes de Estado são: o legislativo, o executivo e o judiciário, independentes e harmônicos entre si; com suas funções reciprocamente indelegáveis. É dada a cada um desses poderes uma função de modo preferencial. O Poder Legislativo tem por finalidade a elaboração de leis; já o Poder Executivo é a conversão da lei em ato individual e concreto; e o Poder Judiciário é a aplicação forçada da lei aos litigantes.

Entretanto, Pinheiro, Vieira, Motta (2011) tem uma visão crítica sobre a divisão dos respectivos três poderes, da execução e do manifesto as atividades necessárias à gestão do Estado em um ambiente de res publica (coisa pública), difundida como a separação dos mesmos, com atribuições importantes, porém não exclusivas a cada um. 
Há em cada Estado três espécies de poder: o poder legislativo, o executivo, e o poder executivo que dependem do Direito Civil. Pelo primeiro poder, o príncipe ou magistrado cria as leis para um tempo determinado ou para sempre, e corrige ou ab-roga aquelas que já estão feitas; pelo segundo, determina a paz ou a guerra, envia ou recebe embaixadas, estabelece a segurança, previne as invasões. Pelo terceiro, pune os crimes ou julga as questões dos indivíduos (MONTESQUIEU, 2006).

Os poderes deveriam estar separados funcionalmente, ou seja, cada função seria atribuída a cada órgão da forma mais especializada possível. E os poderes deveriam estar separados organicamente: os órgãos deveriam ter independência recíproca, num radical pé de igualdade (SOUZA JUNIOR, 2002).

Os poderes funcionam melhor em conjunto, todavia a ação de um detém ou limita a ação do outro. No entanto existe a necessidade de equilíbrio entre os três poderes do Estado, sendo estabelecido e consagrado pela Constituição brasileira (PINHEIRO; VIEIRA; MOTTA, 2011).

\section{Funções do Estado}

A separação dos três poderes foi adotada pela Constituição Federal de 1988, onde desempenham funções atípicas. Entretanto, tanto o judiciário quanto o legislativo o desempenham, tanto suas funções públicas próprias (Judiciária e Legislativa), quanto funções atípicas administrativas (ALEXANDRINO, 2011).

De acordo com Pinheiro, Vieira, Motta (2011) a finalidade da função do poder legislativo é, entretanto, de modo único, pois o Estado exerce essa função por meio da edição de normas tanto gerais quanto abstratas, inovando assim a ordem jurídica e as que estão subordinadas diretamente à constituição.

As funções do Poder Legislativo são de fato legislar e fiscalizar, obedecendo assim às regras constitucionais do processo legislativo e que o Congresso Nacional realize a fiscalização necessária, desde a área financeira até a patrimonial do Poder Executivo (ALEXANDRINO, 2011). 
No Executivo, a função governamental é dividida em destinações políticas e administrativas e que há objetivos diferentes: a intervenção, o fomento e a prestação do serviço público; sendo assim, exercido, através do sistema presidencialista e auxiliado pelos ministros estaduais.

Miranda (2005) diz que o Poder Executivo tem por finalidade de administrar e também legislar, editando as medidas provisórias e as leis, julgando os processos administrativos.

A funcionalidade do judiciário está em aplicar a lei a casos certos, para a segurança da soberania da justiça e a também a realização dos direitos individuais nas relações sociais (MOTA, 2012).

Entretanto, cada um dos poderes de Estado possui uma função significativa, porém não vedada quando há a execução de outras que podem ter pontos de contato ou estritamente ligadas às de outro poder. O legislativo faz a lei, porém o executivo pode propô-la ou vetá-la e o judiciário pode julgá-la nula. O judiciário efetua os julgamentos, contudo pode o legislativo modificar-lhe os critérios legais e o executivo participar de justiça, indultando ou comutando penas (MENEZES, 1996).

\section{Poder Executivo Municipal}

Cada um dos ramos do governo municipal tem missão privativa e própria: a Câmara estabelece normas para a administração; o Prefeito as executa, transformando o mandamento legal, em atos administrativos concretos, assim sendo existe o sistema de separação de funções: executiva e normativa, impedindo que um órgão exerça atribuição do outro, portanto o Prefeito não pode legislar como a Câmara não pode administrar. (MEIRELLES, 1995).

O Poder Legislativo tem assumido e realizado as funções gerenciais em níveis meramente estratégicos, de acordo com seu papel institucional visando ações integradas orientadas para o desenvolvimento local e regional. Superando posturas tradicionais, o legislativo vem ocupando posição de destaque com o envolvimento efetivo da sociedade e a administração pública (KLERING et al., 2011). 
Todavia, sob a ótica da gestão, pode-se afirmar que não existem funções principais ou acessórias para o legislativo, pois seu desempenho e legitimidade residem na realização plena de todas e de forma articulada, quais sejam: função legislativa, função fiscalizadora, função administrativa interna, num papel gerencial estratégico no contexto da administração pública contemporânea (TEMER, 2001).

É preciso perceber as diferentes funções do poder legislativo inserido no processo administrativo ou ciclo gerencial: planejamento, organização, direção-coordenação e controle, com especial destaque para a primeira e a última fase (BRASIL, 1988).

Enquanto instância, sobretudo legisladora e fiscalizadora, o poder legislativo desempenha importante papel no planejamento governamental, especialmente quando aprecia e vota as peças legais integrantes do sistema de planejamento integrado da administração pública (BRASIL, 2000).

\section{Gastos Públicos com Educação e Saúde}

A Constituição Federal de 1988 estabelece, em seu Art. 212, a obrigatoriedade dos municípios, dos Estados e da União aplicarem uma porcentagem mínima das receitas advindas de impostos. A União é responsável pelo ensino superior, da educação profissional e não aplicará menos de 18\%; os Estados cuidam do ensino médio, atuam em parceria com municípios no ensino fundamental e investem menos de $25 \%$ de suas receitas de impostos (BRASIL, 1988).

É necessário que o município deva utilizar recursos para o ensino infantil e fundamental através do FUNDEB, sendo que a destinação é de sessenta por cento na remuneração dos profissionais em educação, e o restante em outras despesas para melhoria e manutenção da educação básica municipal. A Lei das Diretrizes e Bases da Educação Nacional (LDB) ampara as despesas decorrentes das aplicações para a Manutenção e Desenvolvimento Educacional e FUNDEB.

De acordo com a Constituição de 1988; cerca de 15\% dos impostos arrecadados pelo município deve ser destinado às ações e serviços de saúde pública. É importante destacar que é permitido além do mínimo estabelecido, no entanto, não pode ser inferior ao percentual 
mínimo, de acordo com as Diretrizes da Resolução do Conselho Nacional de Saúde.

Para a tomada de decisão e avaliação das políticas públicas é necessário que se obtenha a maior eficiência dos gastos públicos, aprimorando assim a decisão final, e ensejando um excelente resultado (COSTA; CASTANHAR, 2003; JANNUZZI, 2002).

\section{Índice FIRJAN de Desenvolvimento Municipal}

O FIRJAN é a Federação das Indústrias do Estado do Rio de Janeiro é uma entidade privada e filantrópica. A sua missão é a promoção da competitividade empresarial, promovendo a educação e qualidade de vida dos que trabalham na indústria e de toda a sociedade e também para o desenvolvimento do Estado do Rio de Janeiro (FIRJAN, 2012).

O Índice FIRJAN de Desenvolvimento Municipal (IFDM) objetiva em atender o acompanhamento sócio econômico e humano dos municípios do Brasil e exclusivamente do estado do Rio de Janeiro; é um estudo anual e tem a capacidade de retratar o nível de desenvolvimento de cada cidade, e a qualidade de vida da sociedade (FIRJAN, 2012).

O IFDM é um índice é inspirado no Índice de Desenvolvimento Humano, entretanto avalia também o emprego e renda, a saúde e a educação de certo município. Para que se faça uma avaliação isenta e confiável, o cálculo do IFDM utiliza dados administrativos oficiais de declaração obrigatória, disponibilizados pelos municípios e pelos Ministérios do Trabalho, da Educação e da Saúde (FIRJAN, 2012).

Seus resultados classificam em: alto desenvolvimento - resultados superiores a 0,8 pontos; desenvolvimento moderado - compreendidos entre 0,6 e 0,8 pontos; desenvolvimento regular - entre 0,4 e 0,6 pontos e baixo desenvolvimento - resultados inferiores a 0,4 pontos. Sendo assim, quanto mais próximo de um, maior será o nível de desenvolvimento do município e quanto menos próximo de um menor será o desenvolvimento do município (FIRJAN, 2012).

O Índice Firjan de Desenvolvimento Municipal-IFDM seleciona as três principais áreas de desenvolvimento humano: educação, saúde e emprego e renda. O IFDM Emprego \& Renda é a primeira área de atuação do índice acompanhando o mercado formal de trabalho e 
analisando dois subgrupos, emprego formal e renda (remuneração média mensal do trabalhador formal), ambos com o mesmo peso (50\% do total) (FIRJAN, 2012).

A segunda área do IFDM é a Educação, esse índice é composto por dados relativos à educação infantil e ao ensino fundamental e no que tange ao ensino infantil; o número de matrículas em creches e pré-escolas registradas e o número de crianças pertencentes à faixa etária adequada a esta modalidade educacional (entre 0 e 5 anos de idade) Educação Básica (FIRJAN, 2012).

A terceira e última área utilizada para se calcular o IFDM é a saúde que objetiva avaliar a qualidade do Sistema de Saúde Municipal referente à atenção básica. Em relação aos atendimentos as gestantes, eles medem a qualidade do atendimento ao paciente, sendo assim um dos procedimentos considerados mais básicos que um município deve oferecer à sua devida sociedade (FIRJAN, 2012).

\section{Metodologia}

A presente pesquisa tem uma finalidade descritiva e qualitativa; a coleta de dados enfatizará números (ou informações conversíveis em números) que permitam verificar a ocorrência ou não das consequências, e daí então a aceitação (ainda que provisória) ou não das hipóteses (POPPER, 1972).

Richardson (1989) expõe que este método é frequentemente aplicado nos estudos descritivos (aqueles que procuram descobrir e classificar a relação entre variáveis), os quais propõem investigar "o que é", ou seja, a descobrir as características.

A unidade de análise é o município de Petrolina - PE, o qual é considerado de grande porte, com uma população de 319.893 habitantes em 2013, com o PIB acima de R\$ 1 bilhão conforme dados do IBGE (2013).

Por fim, para analisar a relação existente entre as variáveis do estudo, apliucou-se o teste de Kolmogorov-Smirnov para analisar se a distribuição amostral de cada variável apresentava normalidade na distribuição dos dados. Como o resultado do teste foi positivo para todas as variáveis, optou-se por empregar o coeficiente de correlação de Pearson. 
Id on Line Revista Multidisciplinar e de Psicoloqia

Id on Line Multidisciplinary and Psycology Journal

\section{Análise e Discussão dos Dados}

Neste tópico, demonstra a análise e discussão dos dados com a finalidade de alcançar o objetivo delineado nesta pesquisa, que se limita a análise de gastos nos setores de educação e saúde do município de Petrolina-PE, durante os anos de 2005 a 2013.

Tabela 1 - População, valor do PIB, os gastos em educação e saúde e a renda per capita no município de Petrolina-PE nos anos de 2005 a 2013.

\begin{tabular}{|c|c|c|c|c|c|}
\hline ANOS & $\begin{array}{c}\text { POPULAÇÃO } \\
\text { ESTIMADA } \\
\text { (MIL) }\end{array}$ & PIB (EM REAIS) & $\begin{array}{c}\text { GASTO EM } \\
\text { EDUCAÇÃO } \\
\text { (EM REAIS) }\end{array}$ & $\begin{array}{c}\text { GASTO EM } \\
\text { SAÚDE } \\
\text { (EM REAIS) }\end{array}$ & $\begin{array}{c}\text { RENDA PER } \\
\text { CAPITA / } \\
\text { POPULAÇÃO } \\
\text { (EM REAIS) }\end{array}$ \\
\hline 2005 & 253.686 & $\mathrm{R} \$ 1.670 .473 .000,00$ & $\mathrm{R} \$ 35.457 .945,14$ & $\mathrm{R} \$ 38.164 .792,78$ & $\mathrm{R} \$ 6.584,81$ \\
\hline 2006 & 260.004 & $\mathrm{R} \$ 1.772 .665 .000,00$ & $\mathrm{R} \$ 36.272 .673,01$ & $\mathrm{R} \$ 38.160 .652,28$ & $\mathrm{R} \$ 6.817,84$ \\
\hline 2007 & 268.339 & $\mathrm{R} \$ 1.925 .413 .000,00$ & $\mathrm{R} \$ 49.454 .353,54$ & $\mathrm{R} \$ 46.173 .207,31$ & $\mathrm{R} \$ 7.175,30$ \\
\hline 2008 & 276.174 & $\mathrm{R} \$ 2.362 .785 .000,00$ & $\mathrm{R} \$ 59.006 .735,59$ & $\mathrm{R} \$ 49.113 .935,87$ & $\mathrm{R} \$ 8.555,42$ \\
\hline 2009 & 281.851 & $\mathrm{R} \$ 2.324 .726 .000,00$ & $\mathrm{R} \$ 78.952 .670 .31$ & $\mathrm{R} \$ 83.970 .077,55$ & $\mathrm{R} \$ 8.248,07$ \\
\hline 2010 & 293.962 & $\mathrm{R} \$ 3.387 .165 .000,00$ & $\mathrm{R} \$ 96.700 .746,48$ & $\mathrm{R} \$ 89.418 .085,16$ & $\mathrm{R} \$ 11.522,46$ \\
\hline 2011 & 299.752 & $\mathrm{R} \$ 3.756 .440 .000,00$ & $\mathrm{R} \$ 125.953 .464,34$ & $\mathrm{R} \$ 96.017 .482,80$ & $\mathrm{R} \$ 12.531,83$ \\
\hline 2012 & 305.352 & $\mathrm{R} \$ 4.395 .254 .000,00$ & $\mathrm{R} \$ 143.045 .070,47$ & $\mathrm{R} \$ 94.378 .401,88$ & $\mathrm{R} \$ 14.394,06$ \\
\hline 2013 & 319.893 & $\mathrm{R} \$ 4.905 .327 .000,00$ & $\mathrm{R} \$ 150.181 .266,92$ & $\mathrm{R} \$ 92.975 .725,53$ & $\mathrm{R} \$ 15.334,27$ \\
\hline
\end{tabular}

Fonte: elaboração própria (2017).

A Tabela 1 apresenta os dados que serviram de base para a análise dos gastos por função no município analisado e o Produto Interno Bruto produzido no mesmo período.

Observa-se que na tabela acima, a renda per capita relativa aos anos estudados apresentou-se crescente a cada ano, representando uma evolução de aproximadamente $132,87 \%$ entre o primeiro e último ano examinado, é perceptível que a população petrolinense aumentou em cerca de $26,10 \%$, o que certamente influenciou o avanço do PIB, em uma variação de 193,65\%. À medida que, a população cresce, há um aumento no PIB e posteriormente na renda per capita também, dessa forma existe uma necessidade de mais investimentos em educação e saúde. 
Id on Line Revista Multidisciplinar e de Psicoloqia

Id on Line Multidisciplinary and Psycology Journal

Entretanto vale ressaltar que o PIB per capita mede quanto, do total produzido, deveria ou deve ser direcionado para cada pessoa, e que quanto maior for o PIB por pessoa maior deve ser a qualidade de vida e o acesso a serviços, que de certa forma acaba refletindo no Índice de Desenvolvimento Humano do município.

Gráfico 1- Renda per capita do município de Petrolina-PE nos anos de 2005 a 2013 (em reais)

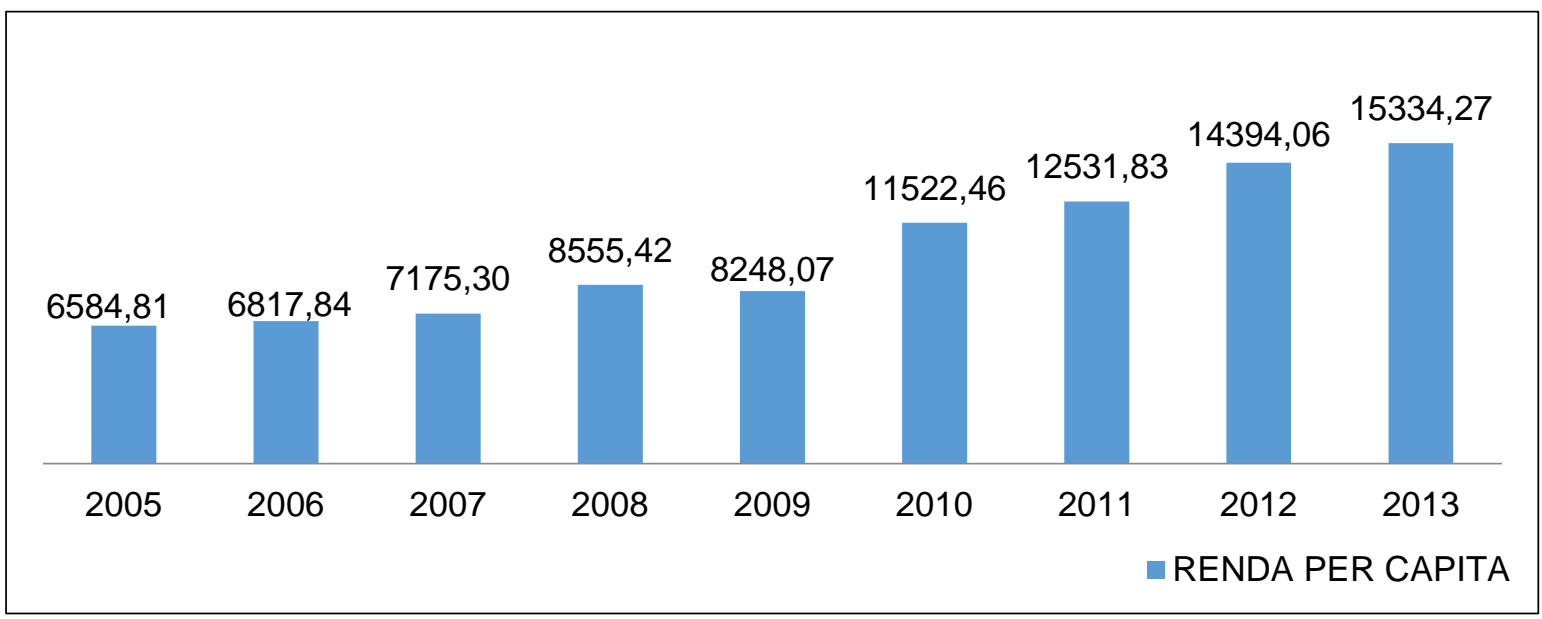

Fonte: elaboração própria (2017).

O Gráfico 1 aponta uma evolução de 129,92\% na renda per capita entre os anos de 2005 a 2008, embora no ano de 2009 houve uma redução na renda per capita, isso é relacionado ao PIB desse mesmo ano que também diminuiu em $-1,61 \%$ em relação ao ano anterior que tinha um crescimento favorável; o aumento da renda per capita não se limita em atingir somente a uma classe social, mas todas as classes, com isso o desenvolvimento econômico tem como objetivo a melhor alocação da riqueza produzida por meio de políticas específicas e bem direcionadas. 
Id on Line Revista Multidisciplinar e de Psicoloqia

Id on Line Multidisciplinary and Psycology Journal

Gráfico 2 - Gasto per capita do município de Petrolina-PE em educação nos anos de 2005 a 2013 (em reais)

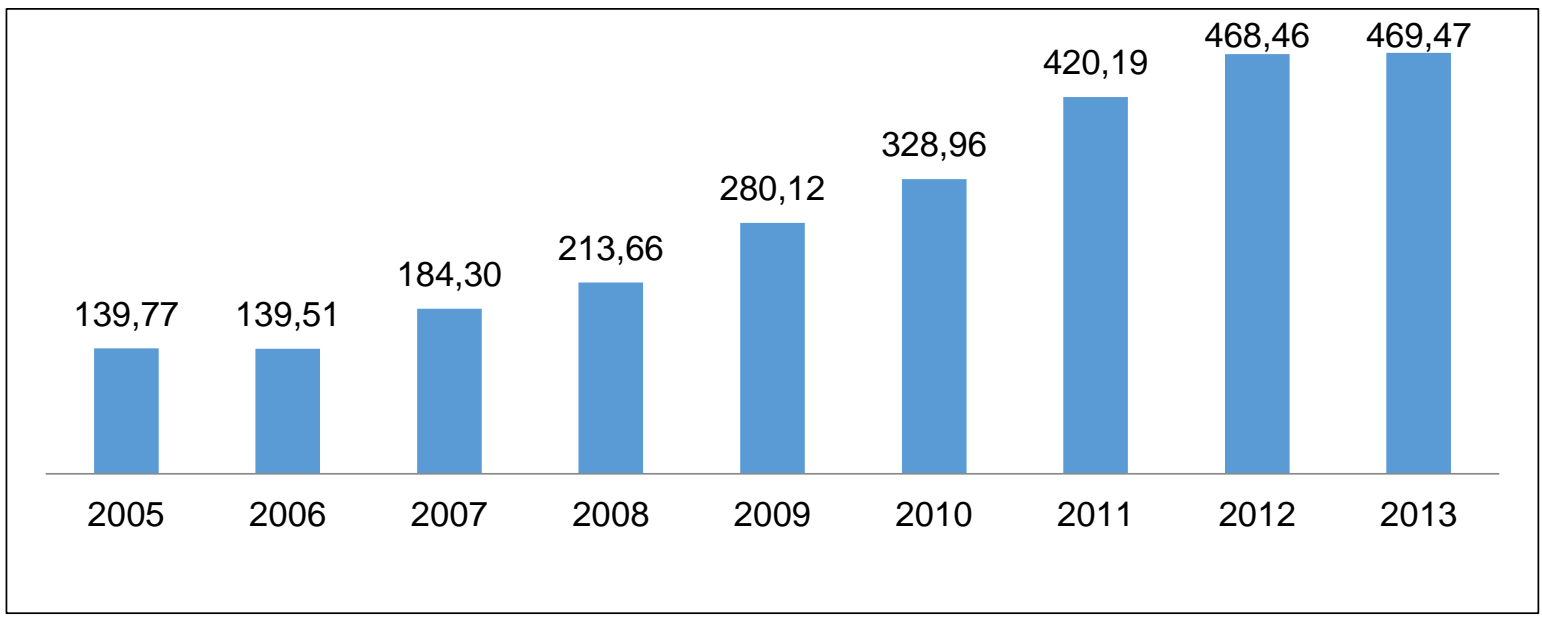

Fonte: elaboração própria (2017).

O Gráfico 2 se refere ao gasto per capita em educação do município de Petrolina-PE, o gasto a esse setor, entre os anos de 2005 e 2006, houve uma redução de $0,186 \%$, mas que a partir de 2007 até 2013 apresentou uma evolução crescente, de 236,51\%, sendo assim, observa-se que houve investimentos incrementais no período analisado, ressaltando que a renda per capita de cada ano estudado supera o gasto per capita em educação dos respectivos anos. Esse gráfico indica que no município estudado houve investimentos em educação e que, por conseguinte teve um gasto per capita significativo, já que os municípios devem gastar $25 \%$ relativa a receita dos impostos, taxas e transferências arrecadadas. Todavia existe uma grande distância entre o gasto e a renda per capita, o gasto cresceu, mas poderia ter sido ainda maior, já que existe uma grande disparidade entre os mesmos. 
Gráfico 3 - Índice FIRJAM de desenvolvimento municipal de Petrolina-PE em educação nos anos de 2005 a 2013.

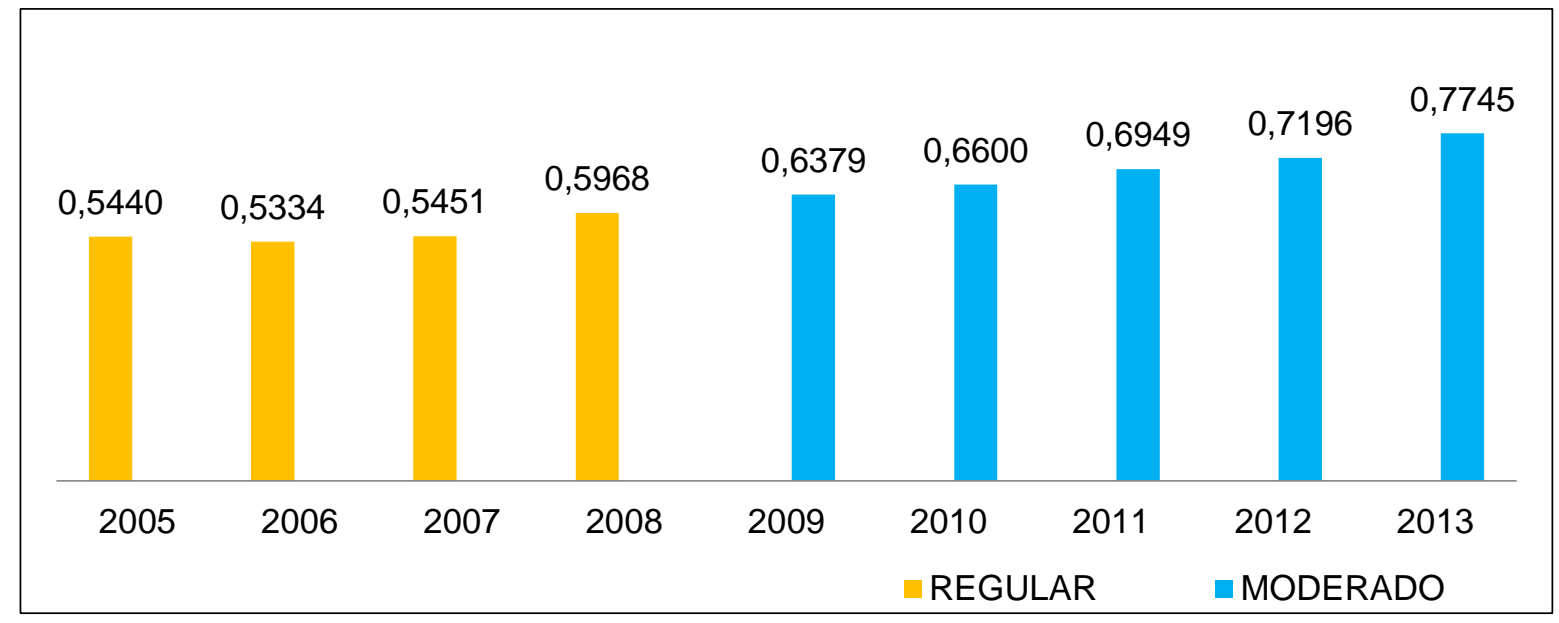

Fonte: elaboração própria (2017).

No Gráfico 3 está descrito o IFDM educação do município de Petrolina-PE no período de 2005 a 2013. O estágio de desenvolvimento dos oito anos segundo o IFDM-FIRJAM (2012) enquadra-se como estágio regular e moderado de desenvolvimento municipal.

Fazendo uma análise do período foi possível verificar que nos anos de 2005 a 2008, os índices variam entre 0,5440 a 0,5968, classificando em regular conforme a FIRJAN (2012); entretanto é verificado na Tabela 1 que houve um gasto nesse setor num total de $\mathrm{R} \$$ 180.191.707,38, sendo assim obteve um aumento nesses dois anos de 66,41\%.

Durante os anos de 2009 a 2013, os índices classificam-se em moderado, alterando de 0,6379 a 0,7745 e um aumento também no próprio gasto dos referidos anos de $\mathrm{R} \$$ 71.228.596,59, conforme Tabela 1; totalizando em um aumento de 90,22\% no gasto em educação, entretanto a renda per capita obteve um aumento durante esses oito anos num total de $132,87 \%$, resultando assim em uma melhoria no índice quanto ao setor de educação.

Portanto esse índice quanto mais próximo de 1, melhor, é visível que houve um crescimento gradativo nesse índice ao longo dos 8 anos, refletindo assim o número de matrículas em creches e pré-escolas registradas no município de Petrolina-PE. 
Gráfico 4 - Gasto per capita do município de Petrolina-PE em saúde nos anos de 2005 a 2013 (em reais)

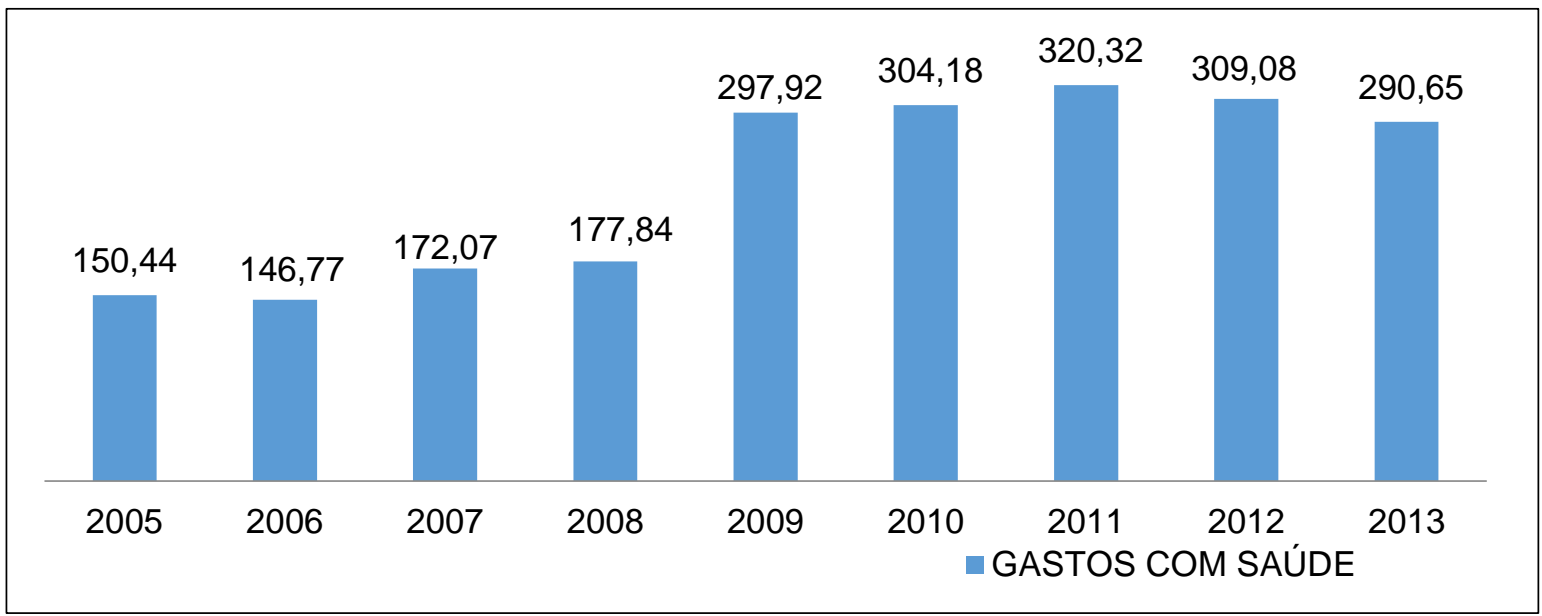

Fonte: elaboração própria (2017).

O Gráfico 4 apresenta o gasto per capita e os gastos referentes à saúde no período de 2005 a 2013 do município de Petrolina-PE; é possível observar que o gasto com saúde obteve um aumento na despesa de 143,62\% nos referidos anos. Entretanto, vale ressaltar que, no ano de 2013 o município obteve uma redução direta no gasto, motivada pela doação do hospital de Traumas para a UNIVASF.

Na saúde o gasto era de $20 \%$ em relação ao total de despesas de 2006 para 31,2\% em 2009, oscilando para 23,8\% no último exercício.

Há um piso de gasto para a área da saúde, a legislação brasileira impõe que o poder público das esferas federal, estadual e municipal devem gastar valores mínimos em saúde, cerca de $15 \%$ dos impostos arrecadados somente serão destinados para ações e serviços de saúde pública, nesse sentido, da mesma forma que na educação, os dados revelam uma grande intervalo entre a renda per capita e os gastos tanto em educação quanto em saúde. 
Gráfico 5 - Índice FIRJAM de desenvolvimento municipal de Petrolina-PE em saúde nos anos de 2005 a 2013.

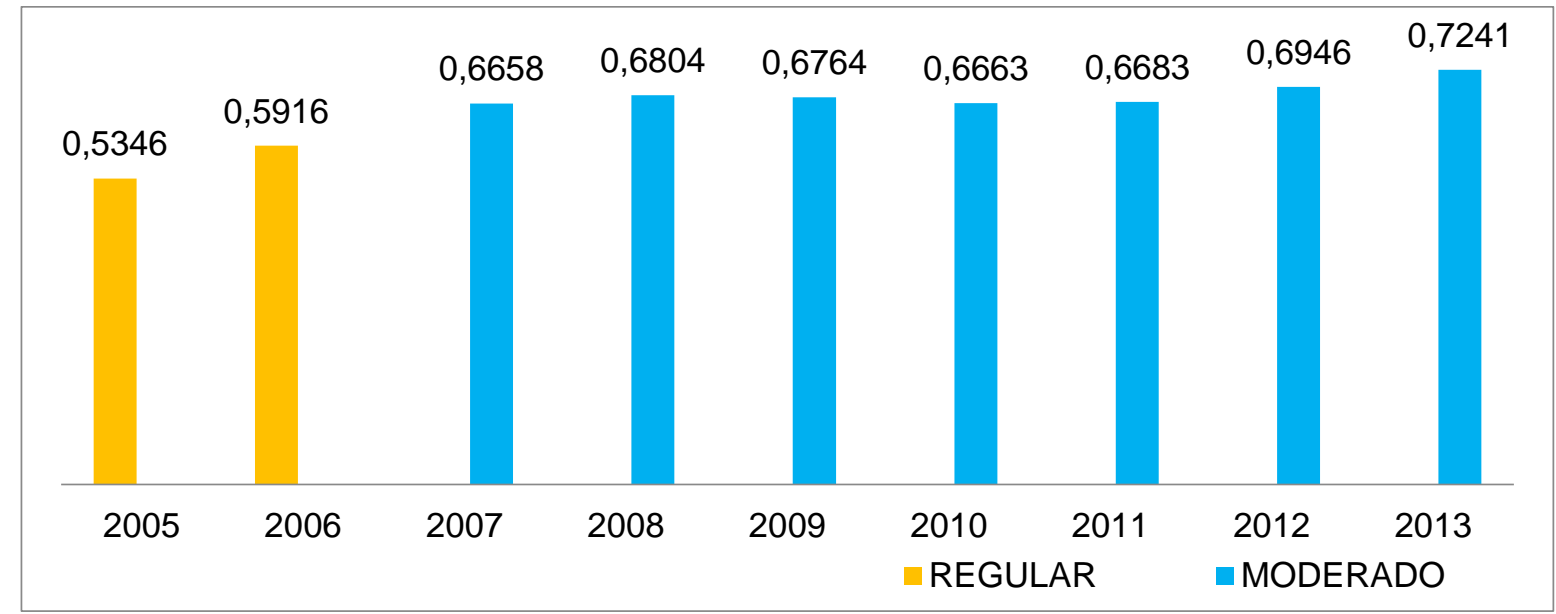

Fonte: elaboração própria (2017).

No Gráfico 5 encontra-se o IFDM saúde dos anos compreendidos entre 2005 a 2013. Segundo os dados da FIRJAN (2012), os índices referentes ao setor da saúde enquadram-se, nos anos de 2005 e 2006 em regular, pois variam de 0,5346 e 0,5916, havendo um gasto de acordo com a Tabela 1 , no período de $\mathrm{R} \$ 76.325 .445,06$.

Acredita-se que houve um investimento na saúde durante esses dois anos, porém não tenha mudado o estágio do índice; no entanto, do ano de 2007 o estágio do índice alterou de regular para moderado, na qual se manteve nesse estágio até o ano de 2013; o gasto totalizado nesse período conforme a Tabela 1 foi de $\mathrm{R} \$ 552.046 .916,10$, totalizando um aumento de 10,72\%, mas que a evolução desse gasto nos anos de 2005 a 2013 foi de 143,62\%, porém o índice manteve estável durante esses respectivos anos, o que motiva uma investigação adicional para levantar elementos empíricos que possam explicar a estabilização da avaliação.

É evidente que o índice com a saúde é satisfatório tão quanto o índice de educação, pois evidencia a qualidade do atendimento ao paciente, mas que os resultados dos índices deveriam ser melhores por que houve investimento mais que suficiente para a população.

O teste Kolmogorov-Smirnov evidenciou a normalidade da distribuição dos dados (pvalor a 2,33\%), bem como o teste de homocedasticidade de Levene apresentou p-valor não 
significativo, o que apontou que os resíduos são homocedásticos. Apresenta-se na Tabela 2, a correlação entre as variáveis do estudo.

Tabela 2 - Correlação entre variáveis.

\begin{tabular}{l|c|c}
\hline \multicolumn{1}{c|}{ Correlação } & Renda per capita & IFIRJAN \\
\hline Gasto per capita em & $0,967^{* *}$ & $0,991^{* *}$ \\
Educação & & \\
\hline Gasto per capita em Saúde & $0,767^{*}$ & $0,675^{*}$ \\
\hline
\end{tabular}

* A correlação é significativa ao nível de $5 \%$

** A correlação é significativa ao nível de $1 \%$

Fonte: elaboração própria (2017).

De acordo com a Tabela 2, os achados indicam uma forte correlação entre gasto per capita em educação e saúde e as variáveis IFIRJAN e Renda per capita. Os resultados apontam que os fatores explicativos dos gastos públicos afetam positivamente as variáveis dependentes deste estudo, corroborando que quanto maior o aporte de recursos do governo em saúde e educação maior será a avaliação de indicadores que avaliam a qualidade desses serviços públicos, bem como a direta relação com a renda. Os altos índices de correlação, sobretudo envolvendo os gastos com educação, corroboram que os dados não possuem problemas de multicolinearidade, garantindo assim a adequação dos resultados.

\section{Considerações Finais}

A Educação e a Saúde são direitos primordiais a qualquer cidadão e principalmente é um investimento aplicado a esses setores por meio de vias governamentais. O Estado deve promover a justiça social, a cidadania, o bem-estar da população e uma contribuição significativa para o desenvolvimento de uma sociedade. Dessa forma, a pesquisa teve por objetivo analisar a utilização dos gastos nessas áreas nos anos de 2005 a 2013 no município de Petrolina-PE. 
Nas áreas investigadas observou-se que houve de fato investimento e que à medida com que a população crescia (cerca de 60.000 pessoas no seu quadro evolutivo de 2005 a 2013), houve também um aumento no gasto (quase 330\%) nos referidos anos e, por conseguinte um crescimento no PIB (Produto Interno Bruto), afetando assim um aumento significativo na renda per capita.

O município de Petrolina-PE obteve os seguintes resultados de acordo com o FIRJAN (2012) na educação de regular (de 2005 a 2008) e moderado (de 2006 a 2013), enquanto isso na saúde obteve regular (de 2005 a 2006) e moderado (de 2007 a 2013); constatou-se também que o município estudado obteve avanços significativos nos gastos com educação, numa proporção de 323,55\% de 2013 em relação a 2005 e na saúde, em torno de 143,62\% nos respectivos anos estudados, segundo a Tabela 1 apresentado nessa pesquisa.

O município não pode registrar os recursos provenientes do governo para diminuírem sua responsabilidade de investimento mínimo, é importante saber quais são os repasses e os valores, para que possa deduzi-los dos resultados contidos nos relatórios de repasses e assim fiscalizar da forma correta.

Foi possível analisar os gastos referentes aos setores indispensáveis à sociedade: educação e saúde e que de fato ocorreram investimentos a esses dois setores, todavia a pesquisa teve suas limitações no acesso aos sites indispensáveis a essa pesquisa. Diante do exposto, recomenda-se para sugestões de abordagens futuras, uma análise alicerçada, principalmente, em variáveis estatísticas dos demais gastos não evidenciados na presente pesquisa e o estudo do índice consolidado, que engloba educação, saúde emprego e renda.

\section{Referências}

ALEXANDRINO, Marcelo; Direito administrativo descomplicado/ Marcelo Alexandrino, Vicente Paulo. - 19. Ed. Ver. E atual. - Rio de Janeiro: Forense; São Paulo: MÉTODO, 2011.

ARISTÓTELES. Política. São Paulo: Nova Cultural, 2004.

BRASIL. Código civil, 2002. Código civil. 53. ed. São Paulo: Saraiva; 2002 Acessado em: 12 julho de 2015. 
BRASIL. Presidência da República. Casa Civil. Subchefia para Assuntos Jurídicos. Constituição da República Federativa do Brasil. 1988. Disponível em:

<http://www.planalto.gov.br/ccivil_03/Constituicao/Constituiçao.htm>. Acessado em: 19 outubro de 2015.

BORGES, T. B., \& Matias, M. A. (2011). Contabilidade gerencial no setor público: o caso de Minas Gerais. Contabilidade Vista \& Revista, 22(3), 73-98.

IBGE - Instituto Brasileiro de Geografia e Estatística/População. Disponível em: http://www.cidades.ibge.gov.br/xtras/populacao.php . Acesso em: 20 jun. 2016.

ÍNDICE FIRJAN DE DESENVOLVIMENTO MUNICIPAL - IFDM. Rio de Janeiro: Firjan, 2012. Disponível em: < http://www.firjan.org.br/ifdm/>. Acesso 20 jun. 2016.

KLERING, L. R. et al. Competências, papéis e funções dos poderes municipais no contexto da administração pública contemporânea, Rio de Janeiro, vol.22 : Editora FGV, 2011.

BRASIL. LEI COMPLEMENTAR 101, de 04 de maio de 2000, Lei de Responsabilidade Fiscal.Disponívelhttp://www.planalto.gov.br/ccivil_03/Leis/LCP/Lcp101.htm>. Acesso em: 19 de outubro de 2015

MEIRELLES, H. L. Direito municipal brasileiro. São Paulo: Malheiros, 1995.

MENEZES, Aderson de. Teoria geral do Estado. 8. ed. rev. atual. Rio de Janeiro: Forense, 1996.

MIRANDA, Henrique Savonitti, Curso de direito administrativo, $3 *$ Ed., rev., Brasília: Senado Federal, 2005.

MONTESQUIEU, Charles Louis de Secondat. Do espírito das leis. São Paulo: Martin Claret, 2006.

MOREIRA, Alexandre Magno Fernandes. Estado, Governo e Administração Pública, Disponível em http://www.lfg.com.br. 28 de novembro de 2008.

MOTA, Pedro Artur Salustino Noronha. O Estado: O Papel de suas funções e de seus três poderes. ConteudoJuridico, Brasilia-DF: 19 out. 2012. Disponivel em: $<$ http://www.conteudojuridico.com.br/artigos\&ver=2.40093\&seo=1>. Acesso em: 18 out. 2015.

RIPSA - REDE INTERAGENCIAL DE INFORMAÇÃO PARA A SAÚDE. Indicadores básicos para a saúde no Brasil: conceitos e aplicações. Rede Interagencial de Informação para a Saúde - RIPSA. 2. ed. Brasília: Organização Pan-Americana da Saúde, 2008. 349 p. 
Id on Line Revista Multidisciplinar e de Psicoloqia

Id on Line Multidisciplinary and Psycology Journal

PINHEIRO, I. A.; VIEIRA, L. J. M.; MOTTA, P. C. D. Mandando Montesquieu às favas: o caso do não cumprimento dos preceitos constitucionais de independência dos três poderes da república. Administração Pública, v. 45, n. 6, p. 1733-1759, 2011.

POPPER, Karl. A lógica da pesquisa científica. 2. ed. São Paulo: Cultrix, 1972

PRESIDÊNCIA DA REPÚBLICA. Lei no 11.494, de 20 de junho de 2007. Regulamenta o Fundo de Manutenção e Desenvolvimento da Educação Básica e de Valorização dos Profissionais da Educação - FUNDEB, Disponível em: <http://www.planalto.gov.br/ccivil_03/_ato2007-2010/2007/Lei/L11494.htm> Acesso 22 julho.2016.

RICHARDSON, Roberto Jarry. Pesquisa social: métodos e técnicas. São Paulo: Atlas, 1989.

SILVA, José Otacílio, Aritósteles: Fundamentos do Poder Político, vol. 04, n Jan. a Jun, Paraná, Cascavel, 2009.

SOUZA JUNIOR, Cezar Saldanha. O Tribunal Constitucional como poder: uma nova teoria da divisão dos poderes. São Paulo: Memória Jurídica, 2002.

TEMER, M. Elementos de direito constitucional. São Paulo: Malheiros, 2001.

Como citar este artigo (Formato ABNT):

REIS, Maria Eduarda F.; SANTOS, Josias S.; LIMA FILHO, Raimundo N..; CAFFÉ FILHO, Hesler P. Gastos em Educação e Saude refletem na evolução de Indicadores Sociais? Uma Análise das Despesas Públicas em Petrolina-PE. Id on Line Revista Multidisciplinar e de Psicologia, Julho de 2017, vol.11, n.36, p.170-188. ISSN: 1981-1179.

Recebido: 27.06.2017

Aceito: 29.07.2017 